\title{
Clinical features and detection of osteomalacia in the elderly
}

\author{
ARnold J. Rosin* \\ M.B., M.R.C.P. \\ Consultant Physician, Guy's Hospital; and \\ Geriatric Department, New Cross Hospital, \\ Avonley Road, London, S.E.14
}

\begin{abstract}
Summary
Fifteen elderly patients with osteomalacia were investigated in $2 \frac{1}{2}$ years in a geriatric unit. Although they all had bone pain the diagnosis in some cases was overshadowed by other common diseases with which they were referred to hospital, such as impaired balance or mental confusion. The bone pain had been present for weeks or months and was often attributed to arthritis. Biochemical investigations showed a low serum calcium and low or low-normal serum phosphate levels and a moderate to large increase in alkaline phosphatase above $15 \mathrm{KA}$ units $/ 100 \mathrm{ml}$. Only six patients had radiological signs of osteomalacia but all had histological evidence on bone biopsy.

Five subjects died within 3 weeks of admission from pneumonia or myocardial infarction. In the other ten, relief of pain occurred within 2-4 weeks of starting vitamin $D$, and bone tenderness disappeared after 2-3 months. The earliest biochemical sign of recovery was the rise in serum phosphate. Calciferol $1.25 \mathrm{mg}$ daily $(50,000$ units of vitamin D) was given for $2-4$ weeks or until there was a rise in the serum phosphate or calcium. One woman of 74 showed resistance to vitamin D associated with renal insufficiency.

Dietary history in seven patients revealed daily vitamin $D$ intakes below 100 units. Four of the fifteen patients had a previous history of partial gastrectomy.

In addition to routine biochemical and X-ray investigations in elderly patients with generalized bone pain, trephine biopsy of the bone is a useful procedure for the diagnosis of osteomalacia.

\section{Introduction}

Bone rarefaction in old age is usually due to osteoporosis. Although the cause of osteoporosis is not certain, it has been suggested that it represents a range of normal ageing changes (Newton-John \& Morgan, 1968: Exton-Smith et al., 1969). Controversy about the pathogenesis of osteoporosis has tended to obscure other conditions which cause bone rarefaction. Osteomalacia is now becoming known as a less common but very important cause of thinning

* Now Physician, Gedera Hospital, Gedera, Israel.
\end{abstract}

of bones in old age (Anderson et al., 1966; Chalmers et al., 1967; British Medical Journal Leader, 1968). It is distinguishable from osteoporosis by its presentation and the distribution of pain, and by the biochemical and radiological features. In old age, osteomalacia may co-exist with osteoporosis (Chapny et al., 1967). It may also be obscured by the simultaneous occurrence of several unrelated diseases, a common happening in the elderly.

The purpose of this paper is to describe the presentation of osteomalacia in old people, pointers to its detection, and the response to treatment. One of the elderly women with resistance to vitamin $\mathrm{D}$ is mentioned in greater detail.

\section{Patients and methods}

Fifteen patients seen in $2 \frac{1}{2}$ years in the Guy's Geriatric Department at New Cross Hospital were found to have unequivocal osteomalacia. Four other patients with clinical and biochemical features of osteomalacia were not included because information about the bone histology was not obtained.

The main criterion for investigation was bone pain, whatever was thought to be the cause. Serum calcium (Ca), phosphate (P) and alkaline phosphatase (AP) levels were estimated in the fasting state on three different occasions and the blood urea, plasma proteins and electrophoretic pattern. If the serum $\mathrm{Ca}, \mathrm{P}$ and AP suggested osteomalacia, iliac crest biopsy was carried out under local anaesthesia with $10 \mathrm{ml}$ of $2 \%$ lignocaine by the technique of Williams \& Nicholson (1963). An 8-mm SackerNordin trephine was used and the bone sections were stained in the undecalcified state by haematoxylin and eosin. Osteomalacia was diagnosed when osteoid borders of at least $22 \mathrm{~m} \mu$ thickness were seen. X-rays were taken of the chest, lumbar spine and pelvis. Most patients were examined for evidence of malabsorption by faecal fat estimations from a 4-day collection and barium studies of the small intestine were done in some of them. Dietary histories were obtained in seven cases from patients and their relatives. All but one of the patients had 
a blood urea under $40 \mathrm{mg} / 100 \mathrm{ml}$, and in the patient with a moderate rise of blood urea, further renal function studies were carried out.

\section{Results}

\section{Sex and age}

There were ten women aged 74-90 (mean 81 years) and five men aged 74-95 (mean 82 years). They formed about $1.5 \%$ of all admissions to the Geriatric Unit in $2 \frac{1}{2}$ years.

\section{Clinical features}

The distribution of the pain is shown in Table 1. Thirteen patients complained of difficulty in walking, either because of general weakness and pain or associated with falling. Table 2 shows the other

TABLE 1. Sites of pain in fifteen patients with osteomalacia

\begin{tabular}{lc}
\hline Site of pain & No. of patients \\
\hline Thighs & 9 \\
Back & 6 \\
Hips & 5 \\
Shoulders & 4 \\
Ribs & 3 \\
Forearm & 1 \\
\hline
\end{tabular}

TABLE 2. Other important illnesses with which fifteen osteomalacic patients presented

\begin{tabular}{lc}
\hline Associated conditions & No. of patients \\
\hline Impaired balance & 6 \\
Confusion & 4 \\
Anaemia & 4 \\
Heart failure & 2 \\
Lung infection & 2 \\
Previous gastrectomy & 4 \\
\hline
\end{tabular}

illnesses with which these patients presented, and how the significance of the bone pain could be overshadowed by cerebral ischaemia or cardiac failure. Table 3 summarizes the distribution of

TABLE 3. Occurrence of fractures in patients presenting with osteomalacia

\begin{tabular}{lc}
\hline Fractures & No. of patients \\
\hline Femur & 3 (in past 2 years) \\
Ribs & 3 \\
Pelvis & 1 \\
Ulna & 1 \\
\hline
\end{tabular}

fractures in five patients. Although proximal thigh weakness was present in several patients, this was often attributed to pain, and none of the electromyograms showed evidence of myopathy. Bone tenderness was often marked, especially from pressure on the rib cage and the femora. The long bones of the arms and the tibiae were sometimes tender. Back pain occurred on movement and not at rest. The duration of the pain was weeks or months, and once it had started, it tended to be constant as long as the patient remained active. The site of the pain sometimes coincided with radiological signs of Paget's disease, or spondylitis, but it remitted after treatment with vitamin D. Bed rest itself was beneficial, and if a patient became immobile for other reasons, the diagnosis of osteomalacia could have been obscured, because the pain became less marked.

\section{Biochemical features}

Fig. 1 shows the range of several serum $\mathrm{Ca}, \mathrm{P}$ and AP values in each case before and after treatment with vitamin $\mathrm{D}$. Both the $\mathrm{Ca}$ and $\mathrm{P}$, were usually low: the AP was often raised but not

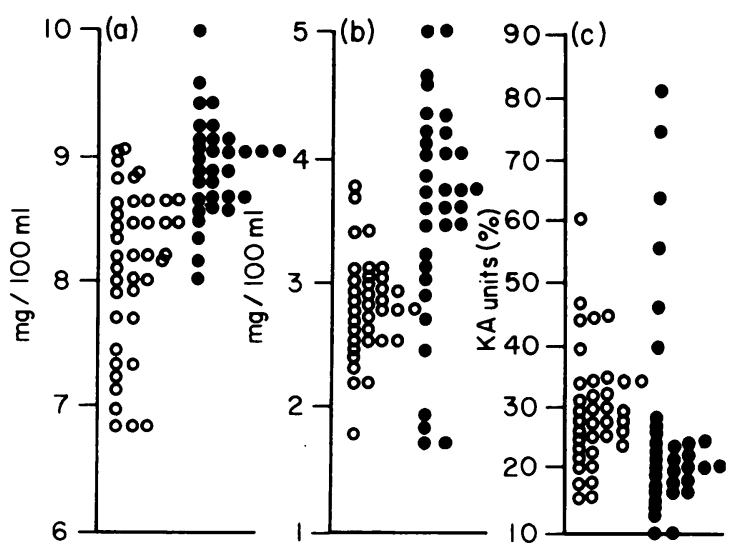

Fig. 1. Serum Ca (a), P (b) and AP (c) values from fifteen patients with osteomalacia before treatment $(O)$ and after treatment (O) with vitamin D.

necessarily very much above $13 \mathrm{KA}$ units $/ 100 \mathrm{ml}$. The earliest response within a few days was a rise in the serum $P$. The serum $\mathrm{Ca}$ rose to normal within 2-3 weeks. In most cases, the AP fell to normal after several weeks, but in two patients there was an initial rise for a few weeks-the 'alkaline phosphatase flare'. The AP returned to normal in one of them after 2 months and the other patient was shown to have vitamin D resistance. Her serum AP became normal only after high doses of vitamin $D$. Faecal fat estimations from 4- or 5-day collections were normal except for one case with a value of $9 \cdot 2 \mathrm{~g} / 24 \mathrm{hr}$. Barium studies of the small bowel in this patient were normal.

\section{Radiology}

Six patients showed X-ray signs of osteomalacia (Figs. 2-5). Looser's zones were present in four and ununited fractures were present in three. Two with ununited fractures had had a partial gastrectomy. Paget's disease was present in three patients. Localized bone tenderness sometimes corresponded 


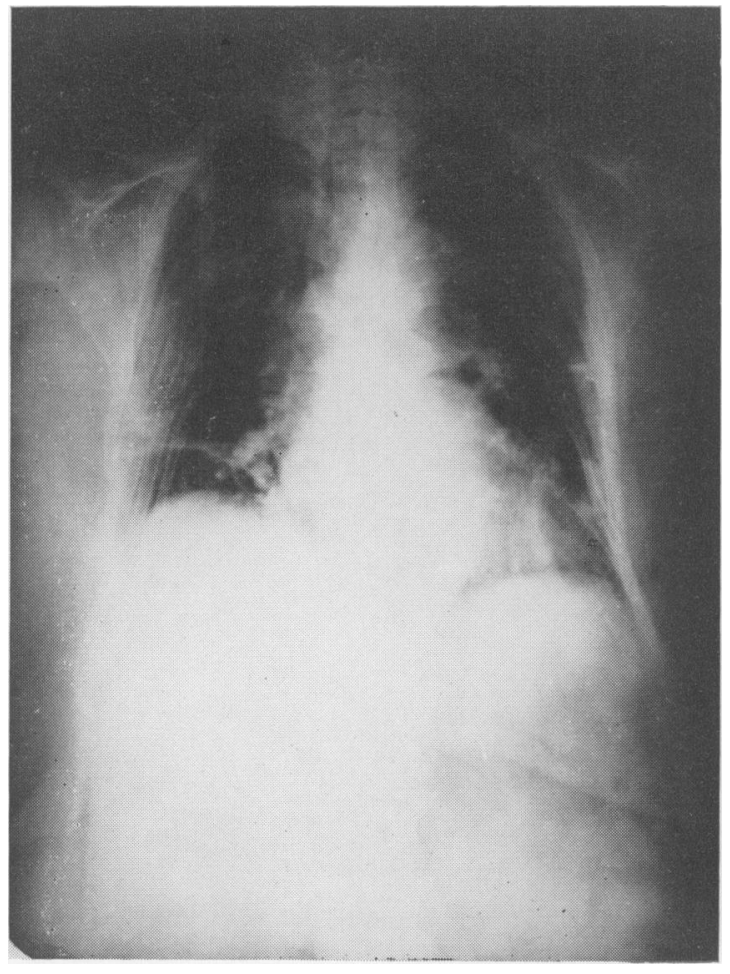

FIG. 2. Pseudofracture of axillary border of right scapula and fractures of right ribs. Coincidental bronchopneumonia.

to the site of a fracture (Fig. 4) but even in the absence of demonstrable feactures, pressure on the ribs was usually painful. Healing and union occurred after treatment. One patient showed the development over 2 years of sclerotic and patchy irregularity of the lumbar vertebrae. In view of a slowly rising blood urea to $100 \mathrm{mg} / 100 \mathrm{ml}$ these signs were taken to represent azotaemic renal osteodystrophy.

\section{Treatment}

Calciferol $1.25 \mathrm{mg}$ (vitamin $\mathrm{D}_{2} 50,000$ units) was given by mouth every day for $2-4$ weeks, and the serum levels of $\mathrm{Ca}$ and $\mathrm{P}$ were checked frequently. When the serum $\mathrm{P}$ or $\mathrm{Ca}$ had risen to normal, one vitamin $A$ and $D$ capsule containing 450 units of vitamin $\mathrm{D}$ was given three times a day or calciferol $1.25 \mathrm{mg}$ (one tablet) was given weekly. No case of hypercalcaemia was encountered.

\section{Response to treatment}

Pain from the long bones usually began to lessen within 2 weeks, although bone tenderness could be present up to 2 months after starting the vitamin $D$. The passive range of joint movements often improved, and walking became easier.

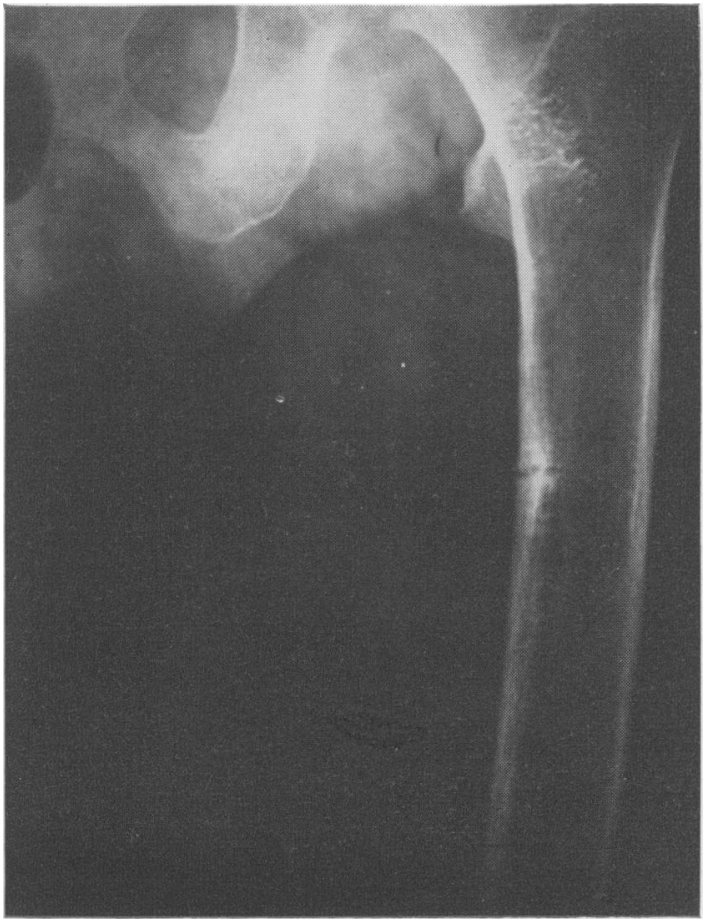

FIG. 3. Pseudofracture, probably at site of nutrient artery. Healing occurred after vitamin D.

Five patients died before treatment was begun, four from pneumonia and one from a myocardial infarction-all between 1 and 3 weeks after admission. In one man of 95 , the serum $P$ remained persistently below $2 \mathrm{mg} / 100 \mathrm{ml}$ although the serum $\mathrm{Ca}$ became normal after 4 months and the AP after 6 months. His symptoms of bone pain disappeared, however, within weeks and he remained free of bone tenderness until his death 1 year later. Autopsy revealed histological changes of osteomalacia in the bone. He had had $27 \mathrm{mg}$ of calciferol in hospital, and it is likely that his forgetfulness accounted for failure to take vitamin D regularly after his discharge.

\section{Vitamin D resistance}

This was encountered in one patient who at first did not show gross features of chronic renal failure. Her case is described in greater detail.

A 74-year-old woman had suffered from progressively severe pain and weakness down the front of her thighs, which after 6 months caused her to fall and to take to her bed. She was tender on pressure on the thighs and the knee jerks were diminished. Her serum Ca was $8.3 \mathrm{mg} / 100 \mathrm{ml}, \mathrm{P} 2.7 \mathrm{mg} / 100 \mathrm{ml}$ and AP $28 \mathrm{KA}$ units $/ 100 \mathrm{ml}$. The serum proteins were $7.0 \mathrm{~g} / 100 \mathrm{ml}$ with a normal electrophoretic strip. The blood urea was $56 \mathrm{mg} / 100 \mathrm{ml}$. X-rays 


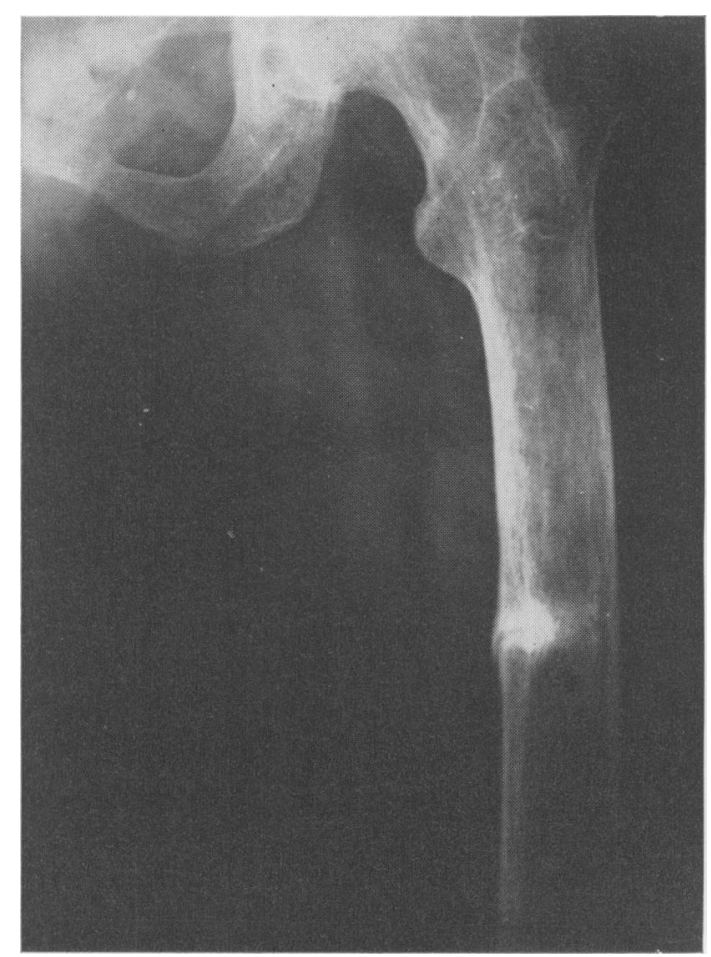

Fig. 4. Incomplete fracture of midshaft of femur without previous trauma. There was considerable tenderness over the site of the fracture, and inability to elevate the leg because of pain.

of the bones were normal. An EMG from the quadriceps muscles was normal. Bone biopsy showed florid osteomalacia. Her symptoms improved with calciferol $1.25 \mathrm{mg}$ daily for 2 months, but although the serum $P$ rose to between 3.4 and $4.4 \mathrm{mg} / 100 \mathrm{ml}$ in the next 6 months, the serum $\mathrm{Ca}$ remained between 8.1 and $8.7 \mathrm{mg} / 100 \mathrm{ml}$ and the AP rose to $80 \mathrm{KA}$ units $/ 100 \mathrm{ml}$.

Her dietary history showed a previously low intake of vitamin D (16 units/day). No evidence of malabsorption was found on X-ray or faecal fat estimations.

Repeat of bone biopsy 6 months after starting calciferol, when a total of $2.5 \times 10^{6}$ units of vitamin $D$ had been given, showed gross osteomalacia and some evidence of hyperparathyroidism.

Further renal studies revealed that the blood urea had risen to $85 \mathrm{mg} / 100 \mathrm{ml}$. The phosphate/creatinine clearance ratio remained high. The acidification test with ammonium chloride lowered the urine $\mathrm{pH}$ to 5.2 within $6 \mathrm{hr}$. The IVP was normal. Apart from some excess taurine no abnormal aminoaciduria was detected on chromatography of the urine. The serum bicarbonate was persistently $18 \mathrm{mEq} / \mathrm{l}$. Urine protein was $550 \mathrm{mg} / 24 \mathrm{hr}$.

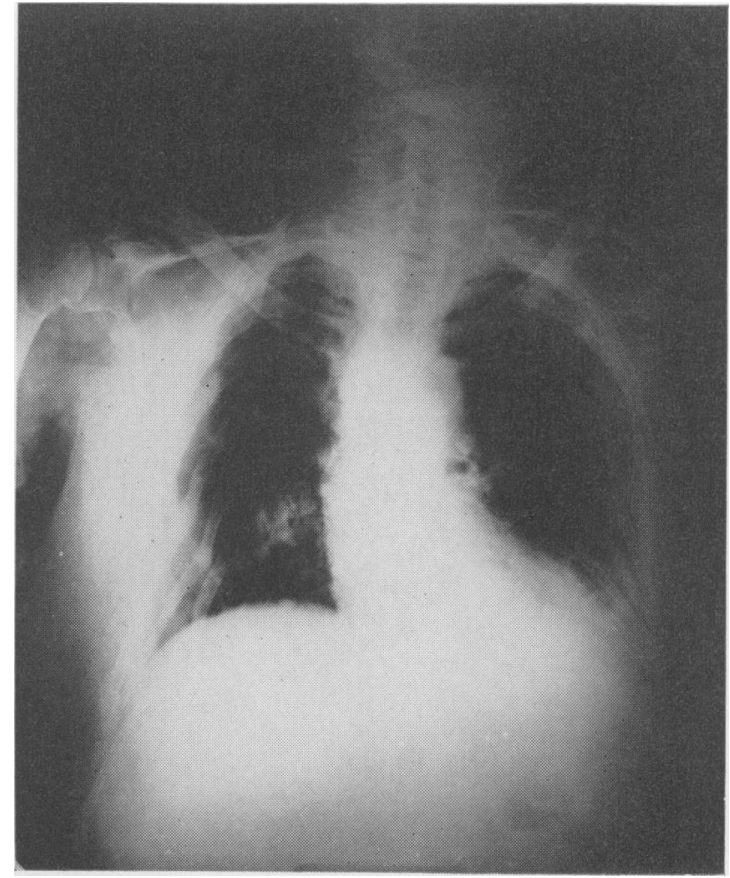

Fig. 5. Ununited fractures of right ribs. Admitted as a case of bronchopneumonia.

It was considered that there was resistance to vitamin $D$. On gradually increasing the daily dose of calciferol to $3.75 \mathrm{mg} /$ day $(150,000$ units), the serum $\mathrm{Ca}$ rose to over $9 \mathrm{mg} / 100 \mathrm{ml}$, the $\mathrm{P}$ remained at $3-4 \mathrm{mg} / 100 \mathrm{ml}$ and the AP fell to between 10 and $15 \mathrm{KA}$ units $/ 100 \mathrm{ml}$. She was given a bicarbonate mixture and her serum bicarbonate rose to $19 \mathrm{mEq} / \mathrm{l}$. She has remained free of bone pain but X-rays of her spine have shown development of patchy sclerosis (Fig. 6). Her blood urea is between 100 and $120 \mathrm{mg} / 100 \mathrm{ml}$.

\section{Diet}

Reliable dietary histories were obtained in seven cases from the patient and relatives. Although their calorie intakes ranged from 1031 to over $2500 /$ day, none of the seven had vitamin D intakes over 100 units/day. The daily contents of vitamin $D$ were $12,16,19,56,79,89$ and 91 units, respectively. Only four of the fifteen patients went out of doors; the rest had been house-bound for months or years.

\section{Discussion}

Apart from being unsuspected, osteomalacia in an old person may not be diagnosed because it is masked by other diseases. Thus in our fifteen patients only seven were referred because of pain, which in three of them had caused the patient to 


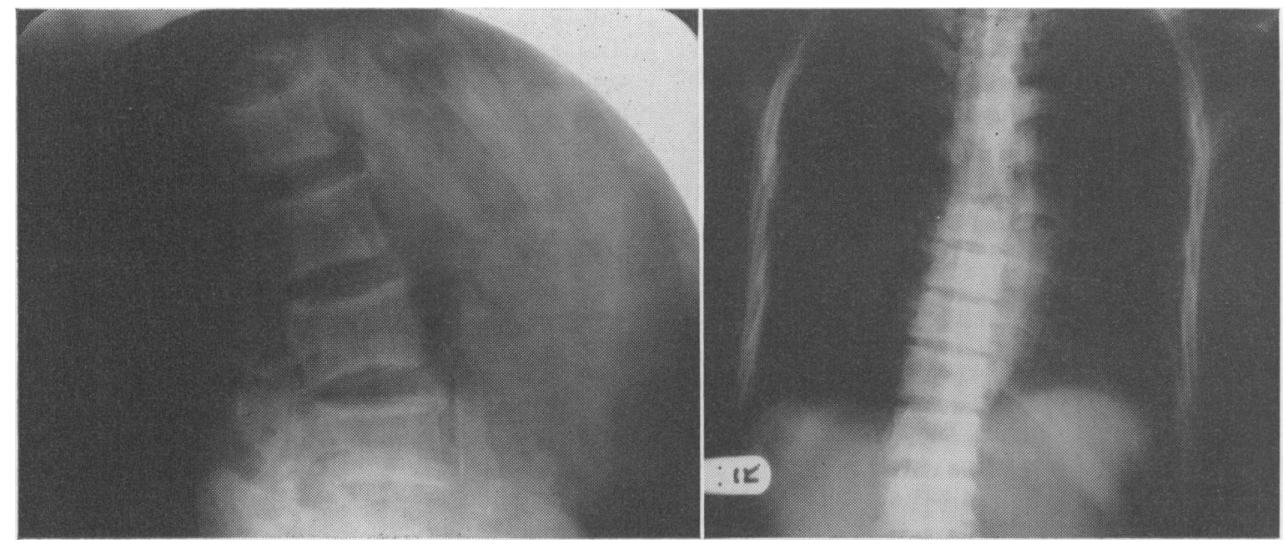

Fig. 6. Lumbar and dorsal spine from patient with vitamin D-resistant osteomalacia, showing alternate sclerotic and rarefied areas of bone ('rugger-jersey' sign).

take to bed after falls. Most of them presented with common, non-specific symptoms of elderly infirm people-falls, 'arthritis', weakness and difficulty in walking about. Important presenting complaints such as heart failure, epilepsy, dementia and pneumonia occurred in the majority. Moreover, there were often co-existing conditions which themselves could cause skeletal pain. Thus Paget's disease was present in three cases involving the spine in one and the hip in two others. Osteoarthritis in the hips was often present, and spondylitis could sometimes have explained back pain.

The approach to this disease in the elderly, therefore, is to suspect it if there is a complaint of generalized aching or pain, or symptoms suggestive of bone pain. Although osteoporosis affects more than half of the population over the age of 75 , pain is relatively uncommon. It occurs in that condition because of vertebral collapse, and occasionally pain may become localized along a rib, either because of a cough-fracture or mechanical stress. Osteomalacia, on the other hand, causes pain by stress on uncalcified bone, so that standing, walking or stress on the bones provokes pain. Characteristically there is tenderness on pressure on the rib-cage and on the long bones of the legs or arms. In most of our cases pain had been present for weeks or months.

Proximal myopathy is not uncommon in osteomalacia, and although we did not detect it in the EMGs of our patients, Smith \& Stern (1967) reported it in eight out of eleven cases of osteomalacia. It occurs frequently in renal osteodystrophy. Ununited fractures were present in three of our fifteen patients, and the failure of a fracture to unite under good mechanical conditions should make one suspect osteomalacia. On the other hand, a search for this condition among fourteen unselected elderly patients with fractured femurs failed to reveal histological evidence of osteomalacia (Missen, Rosin \& Crabbe, unpublished observations 1968). Hodkinson (1968) found no increase in osteoid seams among forty-six old people with fractures and hip operations.

The most convenient screening test is the estimation of the serum $\mathrm{Ca}, \mathrm{P}$ and AP. Although a raised AP has been used as a guide (Hazell \& Otway, 1963), this may fall spontaneously or it may be the result of fractures with a patient with osteoporosis. Unsuspected Paget's disease may also cause a raised alkaline phosphatase. A low serum $\mathrm{Ca} \times \mathbf{P}$ product below 27 has been used as a screening test but this is unreliable. A more significant test has been the demonstration by Whittle et al. (1969) of an early rise in the serum P after one dose of vitamin D in patients with suspected osteomalacia. The correlation between the change in the serum $\mathbf{P}$ and the increase in hydroxyproline excretion suggested to these authors that this may be a useful single routine test for confirming the diagnosis.

Pathognomonic signs are the presence of pseudofractures (Looser's Zones) which were seen in routine X-rays in four of our patients. Histological confirmation of the diagnosis by iliac crest biopsy is a relatively simple but time-consuming procedure. The wide osteoid seam characteristic of osteomalacia may be seen in conditions with a rapid bone turnover, especially Paget's disease. The latter was present in three of our patients, but two of them had florid signs of osteomalacia as well. A quantitative method of assessing osteoid which attempts to distinguish between the two conditions has been described by Paterson, Woods \& Morgan (1968).

\section{Aetiology}

The findings in this small series lend weight to the importance of dietary deficiency in osteomalacia in 
old age (British Medical Journal, 1968, 1969; Lancet, 1969). Isolated cases have been described (Gough, Lloyd \& Wilks, 1964; Dent \& Smith, 1969), where a dietary deficiency through eccentricity or poverty was associated with osteomalacia. It is also known that war conditions in Europe and famine conditions in China produced an increase of the condition in adults.

Another important causative factor in the development of adult osteomalacia is the history of a partial gastrectomy. Thompson (1966) showed that $14 \%$ of 200 post-gastrectomy patients had a raised alkaline phosphatase. Ten of them had osteomalacia proved by bone biopsy and some others with normal bone histology were shown to have negligible vitamin D levels in the plasma. On the other hand, Morgan et al. (1965) found that less than $2 \%$ developed osteomalacia after a Polya gastrectomy. The series of thirty-nine cases of osteomalacia described by Chalmers et al. (1967) from an orthopaedic unit in Edinburgh contained nineteen patients who had had a partial gastrectomy in the past. Four out of our fifteen patients had a history of partial gastrectomy. One of these and six of the others had daily intakes of vitamin $\mathrm{D}$ below the recommended 100 units.

Since there is no clear evidence that post-gastrectomy patients with osteomalacia have steatorrhoea, it has been suggested that nutritional deficiency of vitamin $\mathrm{D}$ may be the basis for the development of the condition. Low fat intake may also predispose to poor vitamin D absorption (Thompson, 1968). Although many elderly people have similar intakes of vitamin D, it is likely that the lack of sunshine as well, and probably individual susceptibility may combine to produce critical vitamin D deficiency.

Resistance to the action of vitamin D is uncommon in the elderly. The case of vitamin $D$ resistance reported in our paper was unusual in that she had a low dietary intake, but the bony and biochemical signs did not remit until large doses of vitamin D were given (between 100,000 and 150,000 units daily). There was no evidence of malabsorption, but she had a slowly rising blood urea, from 50 to $120 \mathrm{mg} / 100 \mathrm{ml}$. On the other hand, she did not have the high serum $\mathbf{P}$ characteristic of chronic azotaemia and her resistance to vitamin $\mathrm{D}$ may have been caused by the acidosis due to chronic renal failure.

\section{Conclusion}

Although malnutrition seems to play a role in producing osteomalacia in old people, its detection from knowledge of the patient's dietary habits may be difficult. The possibility of osteomalacia should be considered if there is bone pain, and repeated serum estimation of $\mathrm{Ca}, \mathrm{P}$ and $\mathrm{AP}$ should be performed. Histological confirmation by bone biopsy is important. The patient's serum biochemical findings should be seen to return to normal by treatment with vitamin $\mathrm{D}$ before one can assume that the condition has been cured.

\section{Acknowledgments}

I am grateful to Dr H. A. Sissons of the National Orthopaedic Hospital for histological examination of the bone biopsy specimens, and for helpful discussion. Thanks are due to Dr G. A. K. Missen of the Morbid Anatomy Department at Guy's Hospital for some of the histological material and to Dr J. Fullerton, Pathologist at St Olave's Hospital for the biochemical estimations.

I thank the Department of Medical Illustration at Guy's Hospital for the diagrams and photography.

\section{References}

Anderson, I., Campbell, A.E.R., Dunn, A. \& Runciman, J.B.M. (1966) Osteomalacia in elderly women. Scottish Medical Journal, 11, 429.

British Medical Journal (1968) Osteomalacia in Britain. 2, 130. British Medical Journal (1969) Nutrition and age. 2, 396.

Chalmers J., Conacher, W.D.H., Gardner, D.L. \& Scott, P.J. (1967) Osteomalacia-a common disease in elderly women. Journal of Bone and Joint Surgery, 49B, 403.

Chapny, P., Chapny M.C., Bernard, J. \& Parsu, D. (1967) Senile osteomalacia-with a report of 15 cases. Revue française de Gérontologie, 13, 147.

DENT, C.E. \& SMITH, R. (1969) Nutritional osteomalacia. Quarterly Journal of Medicine, New Series, 38, 195.

Exton-Smith, A.N., Millard, P.H., Payne, P.R., Wheeler, E.F. (1969) Pattern of development and loss of bone with age. Lancet, ii, 1154.

Gough, K.R., Lloyd, O.C. \& Wilks, M.R. (1964) Nutritional osteomalacia. Lancet, ii, 1261.

Hazell, K. \& OATway, A.W.N. (1963) Senile osteoporosis and osteomalacia. Gerontologia clinica, 5, 203.

Hodkinson, M.F. (1968) Communication to British Geriatric Society.

Lancet (1969) Dietary osteomalacia. i, 1037.

Morgan, D.B., Paterson, C.R., Woods, C.G., PulverTAFT, C.N. \& FourmaN, P. (1965) Search for osteomalacia in 1,228 patients after gastrectomy and other operations on the stomach. Lancet, ii, 1085.

Newton-John, H.F. \& Morgan, D.B. (1968) Osteoporosis: disease or senescence. Lancet, $\mathbf{i}, 232$.

Paterson, C.R., Woods C.A. \& Morgan, D.B. (1968) Osteoid in metabolic bone disease. Journal of Pathology and Bacteriology, 95, 449.

SMITH, R. \& STERN, G.M. (1967) Myopathy, osteomalacia and hyperparathyroidism. Brain, $90,593$.

Thompson, G.R. (1968) Studies in the absorption and metabolism of vitamin $\mathrm{D}$ after gastric surgery. Postgraduate Medical Journal, 44, 626.

Whittle, H., Blair, A., Neale, G., Thalassinos, N., Mclaughlin, M., Marsh, M.N., Peters, T.J., WedZICKA, B. \& Thompson, G.R. (1969) Intravenous vitamin D in the detection of vitamin D deficiency. Lancet, $\mathbf{i}, 747$.

Williams, J.A. \& Nicholson, G.I. (1963) A modified bone biopsy drill for out-patient use. Lancet, i, 1408. 